Trends Mol Med. 2014 July ; 20(7): 375-384. doi:10.1016/j.molmed.2014.04.004.

\title{
Defining the Toxicology of Aging
}

\author{
Jessica A. Sorrentino, $\mathrm{PhD}^{1,4}$, Hanna K. Sanoff, MD, $\mathbf{M P H}^{2,4}$, and Norman E. Sharpless, \\ MD $^{1,2,3,4}$ \\ ${ }^{1}$ The Curriculum in Toxicology, University of North Carolina, Chapel Hill, North Carolina, \\ 27599-7270, USA \\ 2Department of Medicine, University of North Carolina School of Medicine, Chapel Hill, North \\ Carolina, 27599-7264, USA \\ ${ }^{3}$ Department of Genetics, University of North Carolina School of Medicine, Chapel Hill, North \\ Carolina, 27599-7264, USA \\ ${ }^{4}$ The Lineberger Comprehensive Cancer Center, University of North Carolina School of Medicine, \\ Chapel Hill, North Carolina, 27599-7295, USA
}

\begin{abstract}
Mammalian aging is complex and incompletely understood. While significant effort has been spent addressing the genetics or, more recently, the pharmacology of aging, the toxicology of aging has been relatively understudied. Just as an understanding of 'carcinogens' has proven critical to modern cancer biology, an understanding of environmental toxicants that accelerate aging ('gerontogens') will inform gerontology. In this review, we discuss the evidence for the existence of mammalian gerontogens, as well as describe biomarkers needed to measure the agepromoting activity of a given toxicant. We focus on the effects of putative gerontogens on the in vivo accumulation of senescent cells, a characteristic feature of aging that plays a causal role in some age-associated phenotypes.
\end{abstract}

\section{Keywords}

Gerontogen; p16 ${ }^{I N K 4 a} ; C D K N 2 a$; toxicology; senescence; biomarkers

\section{How do toxicants affect the molecular aging phenotype?}

Aging is a complex process reflecting the interplay of genetic and environmental factors. In humans, this intricacy underlies a considerable heterogeneity in the pace of physiological aging: while one disease-free 75 year old may play singles tennis and volunteer at preschool, another may require a walker and be dependent for self-care. A critical need in

(C) 2014 Elsevier Ltd. All rights reserved

Corresponding author: Norman E Sharpless (Norman_Sharpless@med.unc.edu).

Publisher's Disclaimer: This is a PDF file of an unedited manuscript that has been accepted for publication. As a service to our customers we are providing this early version of the manuscript. The manuscript will undergo copyediting, typesetting, and review of the resulting proof before it is published in its final citable form. Please note that during the production process errors may be discovered which could affect the content, and all legal disclaimers that apply to the journal pertain. 
gerontologic research is an understanding of how host genetics and environmental exposures interact over the organismal lifespan to produce common phenotypes of aging such as increased risk to certain diseases, loss of regenerative capacity and frailty (see Glossary).

To address this need, there has been significant effort to use classical genetic analyses to study aging across species. In C. elegans, S. cerevisiae, and Drosophila, a large number of genes have been identified through unbiased approaches which modulate lifespan through an effect on insulin growth factor 1 (IGF-1)/Insulin signaling and metabolism [1-5]. These studies have been supported by analyses of genetically engineered mice as well as studies of human progerias, also identifying genes and pathways reproducibly associated with lifespan in mammals [6]. Recent human genome-wide association studies (GWAS) focused on ageassociated phenotypes have also proven informative regarding human aging [7, 8].

In addition to these genetic results, more recently, informative studies of pharmacologic agents suggest number of compounds affect mammalian aging. Unlike toxicology, pharmacology studies the effect of compounds intentionally given for a treatment purpose, and in the modern era, such agents usually engage a known 'target' molecule. The NIA Interventions Testing Program has begun to serially test compounds to examine their effect on the lifespan of both male and female mice. Such efforts have clearly defined a role for metabolic regulators, such as metformin and rapamycin $[9,10]$, in the modulation of mammalian lifespan or aging. While these genetic and pharmacologic approaches have made unquestioned contributions to the study of aging, toxicology, the study of unintended exposures to toxicants, has been under-utilized for this purpose.

The concept of a "carcinogen", environmental toxicants that promote cancer, has been a critical component to modern cancer biology. For example, the observation by Sir Percival Pott that chimney sweeps in London exhibited an increased risk of scrotal cancer provided the foundation for cancer epidemiology [11]. Additionally, work showing that tobacco exposure significantly increases the risk of lung cancer led to the identification and characterization of numerous carcinogens in tobacco smoke [12]. The appreciation that environmental agents can play an important causal role in carcinogenesis has led to an advanced set of carcinogenicity assays, both in vitro and in vivo, to assess the cancer promoting potential of any new compounds or chemicals released into the environment. While an understanding of the nature of carcinogens is highly sophisticated, our understanding of how toxicants may promote aging is nascent.

The concept that environmental exposures can promote aging is not new. For example, Tom Perls noted that the rate of physiological aging is determined largely $(50-75 \%)$ by nongenetic factors [13]. Moreover, George Martin reasoned that there must be environmental agents that accelerate the rate of molecular aging, and coined the term "gerontogen" for such age-promoting toxicants. He presciently suggested that tobacco smoke might represent a gerontogen, based on its ability to promote disparate age-associated conditions (e.g. cancer, atherosclerosis, emphysema and pulmonary fibrosis) [14]. According to this theory, differential exposure to largely unknown gerontogens explains much of the non-genetic variation in the rates of human physiological aging. 
There has been some work to address the toxicology of aging, with the bulk of this effort focused on DNA damaging agents. This focus has been reasonable given evidence suggesting that DNA damage modulates mammalian aging, although the precise mechanistic link between DNA damage and aging remains unclear $[15,16]$. Likewise, there are wellrecognized in vitro assays for the DNA damage response (e.g. phospho-H2AX, quantification of specific DNA adducts) and mutagenic potential (e.g. Ames mutagenesis test), but it is not known how to use these results in the context of aging. The approach of serially testing compounds in rodents long-term and then phenotyping for aging has not been widely employed, given that the design and interpretation of such experiments is challenging [17]. The limited amount of prior work in this area brings into sharp relief the fact that the identification of gerontogens has been hampered by a lack of good biomarkers for molecular age (not due to lack of effort), which in turn reflects an incomplete understanding of the basic science mammalian aging.

In this review, we will summarize efforts in mammals to understand how environmental exposures accelerate or retard aging. The concept of biomarkers features prominently in this discussion, as a means to measure various aspects of aging is critical to this line of research. We will discuss how a new biological understanding, particularly the role of cellular senescence in aging, has facilitated the development of aging biomarkers. These methods will translate to human studies aiming to define how unintended environmental exposures contribute to the pace of human aging.

\section{Aging, senescence, and p16 INK4a}

No single molecular pathogenic pathway accounts for all aspects of aging. Several lines of evidence, however, suggest that activation of $p 16^{I N K 4 a}$ expression and/or cellular senescence are important contributors to some age-associated conditions. Of relevance to this review, the accumulation of cells with characteristics of senescence in vivo is now measurable, providing a means to determine if a noxious exposure accelerates these aspects of aging mediated by senescence. It is almost certainly true that there are gerontogens that do not influence senescence, and therefore focusing solely on senescence necessarily provides an incomplete view of the toxicology of aging. Many of the concepts described in this review, however, will be relevant to this sort of senescence-independent gerontogen, as biomarkers for these processes are described.

Cellular senescence, described in the 1960's by Hayflick and colleagues, represents a permanent form of cellular proliferative arrest thought to be important in tumor suppression [18]. There are many factors that cause senescence in vitro including telomere shortening $[19,20]$, induction of oncogenes [21, 22], oxidative stress [19], DNA damage [23, 24], and epigenetic alterations [25], but the importance of these with regard to senescence induction in vivo has not been clearly defined. Senescent cells are characterized by phenotypic changes; for example increased expression of $\beta$-galactosidase ( $\beta$-gal) activity and the elaboration of many pro-inflammatory cytokines (e.g. interleukin 6 (IL6), IL8, macrophage inflammatory protein 1 (MIP1), vascular endothelial growth factor 1 (VEGF1)) comprising the senescence-associated secretory phenotype (SASP) (Figure 1). Although initially viewed as an in vitro artifact, recent work suggests that senescence occurs in vivo in response to 
certain insults, and that senescent cells accumulate with aging, although unequivocal resolution of this issue has proven troublesome due to the limited nature of in vivo markers of senescence.

Recent work in mice and humans, in particular, has suggested that expression of the INK4a/ARF (or CDKN2a) locus is intimately associated with senescence and aging. This locus, which encodes $\mathrm{p} 16^{\mathrm{INK} 4 \mathrm{a}}$, is generally repressed in normal adult tissues, but in the presence of certain cellular stresses, expression is potently induced. Expression of p16 $6^{\mathrm{INK} 4 \mathrm{a}}$ inhibits the activity of proliferative cyclin dependent kinases 4 and 6 , which in turn activates retinoblastoma $(\mathrm{RB})$ family proteins to inhibit cell cycle progression, inducing a proliferation arrest at the G1 to S boundary. Importantly, even in cell types where sustained growth arrest is induced by other pathways (e.g. p53), the prolonged expression of p16 $6^{\mathrm{INK} 4 \mathrm{a}}$ is observed in almost all senescent cells. Silencing of the locus requires the coordinated and persistent activity of the Polycomb group complexes (PcG), which covalently modify histone tails to place repressive marks (H3K27 and H2AK119) at the INK4a/ARF locus (Figure 2). Expression of the INK4a/ARF locus requires loss of this silencing, and is also associated with binding of transactivating transcription factors [26, 27]. However, it is not known how the myriad of cellular stresses that activate the INK4a/ARF locus function with regard to binding of transcription factors or loss of $\mathrm{PcG}$ silencing. Moreover, it is uncertain what triggers the transition from a quiescent (transient growth arrest) to senescent state (permanent growth arrest), although it is clear this requires a prolonged growth arrest (greater than 5 days) as well as signaling independent of the INK4a/ARF locus [28]. Importantly, expression of $\mathrm{p} 16^{\mathrm{INK} 4 \mathrm{a}}$ is not a perfect marker of senescence: expression in non-senescent cells is well-described [29], as is senescence occurring independently of p16 ${ }^{\mathrm{INK} 4 \mathrm{a}}$ expression $[19,30]$.

Substantial research supports the model that INK4a/ARF activation is associated with organismal aging and plays a causal role in the process. Firstly, expression of p16 $6^{\mathrm{INK} 4 \mathrm{a}}$, as well as other senescence markers, accumulates with aging [31-33] and this rate of accumulation is modulated by age-modifying stimuli such as caloric restriction [31] and smoking [32, 34]. Murine genetic studies have indicated that expression of $\mathrm{p} 16^{\text {INK4a }}$ plays a causal role in the age-associated decline of replicative function in several tissues including neural stem cells [35], hematopoietic progenitors [36], lymphocytes [32, 37], muscle stem cells [38] and pancreatic $\beta$-cells [39]. Pharmacologic and genetic approaches to decrease the number of $\mathrm{p} 16^{\text {INK4a }}$-expressing cells in vivo can lessen age-associated phenotypes such as sarcopenia and hypo-replication of T-lymphocytes and pancreatic $\beta$-cells [33, 40, 41]. For

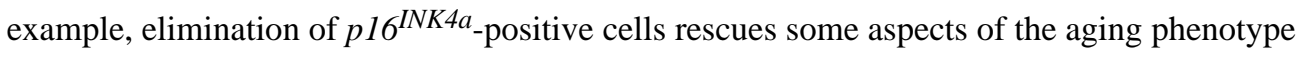
in a progeroid strain of mice [42]. Finally, studies of a few million humans in GWAS have compellingly linked regulators of senescence (e.g. INK4a/ARF and Telomerase reverse transcriptase) to a variety of age-associated diseases such as cancer, atherosclerosis, type 2 diabetes mellitus, and glaucoma (reviewed in [7]). In aggregate, these results from disparate genetic systems suggest that expression of $p 16^{I N K 4 a}$ contributes to the manifestations of human aging, possibly through the promotion of senescence in vivo.

The activation of senescence is currently believed to contribute to mammalian aging through at least two mechanisms. First, formerly proliferative cells that activate high-level 
expression of anti-proliferative proteins like $\mathrm{p} 16^{\mathrm{INK} 4 \mathrm{a}}$ cannot further divide. This loss of replicative capacity in somatic self-renewing compartments leads to impaired homeostasis and loss of regenerative capacity [43]. A second mechanism whereby senescence may promote aspects of aging is through the elaboration of effector molecules associated with the SASP. SASP cytokines are generally pro-inflammatory, and have been suggested to promote some characteristics of aging such chronic inflammation and augmented tumorigenesis [44]. It is likely both processes contribute to aspects of mammalian aging, although the relative contributions of replicative 'Loss-of-Function' versus SASP 'Gain-of-Function' in specific aging tissues are largely unknown.

\section{Measuring aging and senescence}

While it is clear that certain environmental exposures (e.g. cigarette smoke, UV light) can lead to well-defined pathologies (lung and skin cancer), the relationship of such diseasepromoting toxicants to aging is not known. For example, cigarette smoking causes emphysema, but it is uncertain if the pathogenesis of emphysema has molecular similarities to pulmonary aging (i.e. smoking is 'gerontogenic'), or if it reflects a parochial process specific to tobacco-induced lung injury. One means to address this question would be to have molecular biomarkers to assess aspects of physiological aging.

In general, there are a few properties of aging biomarkers to be considered for the purpose of measuring gerontogenicity. First, such a marker should be related to aging in several organs, and should not be tissue or disease specific. For example, an age-dependent increase in $\beta$ amyloid in the brain is strongly correlated with Alzheimer's disease and likely plays a causal role in the process [45, 46], but does not appear to be a good biomarker of aging in other tissues. Accumulation of dolichol, an essential alcohol for glycoprotein biosynthesis, in the liver is a similar tissue-specific example [47,48]. While these biomarkers might be of great value for predicting certain tissue-specific disease states, they would not be generally useful as aging biomarkers.

An even more important and more limiting criterion is the need for the biomarker to play a causal role in aging. That is, there are a tremendous number of cytokines, protein aggregates, epigenetic marks and RNA transcripts whose abundance changes with aging, some in a very dynamic way. To be a good marker of physiologic age, however, the change in marker abundance should causally contribute to phenotypes of aging. For example, certain markers might merely reflect the passage of time, and therefore would be expected to correlate very strongly with chronologic age. While such a marker might be useful in a forensic setting (e.g. to identify the age of an unidentified corpse), such a test would not be more useful than chronological age as a marker of aging physiology. Likewise, a biomarker might correlate with a specific cellular process; for example the way telomere length correlates with prior replicative history of a self-renewing cell. Such a marker might be a good predictor of physiologic age in some circumstances; for example where one component (i.e. number for replications) predicts future replicative capacity, but might be relatively invaluable for other aspects of aging physiology. Given that aging likely reflects distinct pathologic processes at work in different tissues, it is unlikely that any single biomarker will fully capture all aspects of physiological age. A subset of a number of 
proposed biomarkers of molecular aging is shown in Table 1, including a summary of their relative merits and weaknesses.

Given the aforementioned evidence that senescence occurs across many tissues and plays a causal role in some aspects of aging, there has been particular interest in the measurement of senescence-associated (SA) events as biomarkers of aging. Some of the markers of cellular senescence that increase with aging in humans and mice include SA $\beta$-galactosidase staining [49], tissue levels of SASP factors [50, 51], telomere foci [52], and expression of $p 16^{I N K 4 a}$ [31-33]. Although each of these markers is related to senescence, they have been of varying utility in vivo. Historically, SA- $\beta$-galactosidase staining has been one of the most useful ways to measure senescence in cultured cells. In vitro, this marker is very consistent, but the in vivo interpretation of this assay has proven difficult as specific tissues vary tremendously in their expression of this enzymatic activity. In humans, decreased leukocyte telomere length (LTL) is inversely correlated with chronological age in a variety of studies (e.g. [53, 54]). Undoubtedly, telomere shortening occurs with aging and is accelerated with replicative stress, but its utility as a biomarker has been questioned [55]. For example, dramatic physiologic changes of bone marrow stem cells occur with aging and are associated with age-induced hematopoietic dysfunction, but these changes do not generally correlate with LTL in hematopoietic elements [56, 57]. Second, while telomere length decreases with aging in population-based studies, LTL varies substantially among individuals of the same age, and the absolute change is relatively small over an organism's lifespan $[55,58,59]$. Lastly, methods for determining LTL are difficult and expensive, making it less appealing as a high throughput biomarker. Levels of IL-6 and other SA-cytokines correlate with aging. Although the SASP in aggregate may represent a very important contributor to aging physiology, the data for a pronounced role of any specific SASP component playing a causal role in aging are not strong. Additionally most of these SA-cytokines are acute phase reactants that exhibit a marked change in expression in response to viral infection and other inter-current illness unrelated to aging. Therefore, these SA-cytokines have shown very limited utility as aging biomarkers.

Two more recent markers, $p 16^{I N K 4 a}$ expression and changes in DNA methylation, have shown some promise in human studies. Expression of $p 16^{I N K 4 a}$ has been widely used in vivo as a marker of senescence in humans and rodents. This approach has some advantages: p16 $6^{I N K 4 a}$ expression changes more than 10 -fold with aging, strongly correlates with chronological age, appears to play a causal role in some age-related phenotypes and is intimately linked with senescence. Expression can be measured by RT-PCR or IHC in multiple tissues where senescent cells are thought to accumulate with aging, with reports of utility in several human tissues including kidney [60, 61], skin [62, 63], and peripheral blood T-lymphocytes $[32,51,64]$. IHC testing of $\mathrm{p} 16^{\mathrm{INK} 4 \mathrm{a}}$ is non-quantitative and can show ageindependent staining (e.g. in the setting of neoplasia). The major limitation of the quantitative RT-PCR assay is the need for good quality RNA from homogenous cells. For example, measurement in RNA from whole blood has been unreliable, and informative analyses of this tissue have generally required isolation of peripheral blood $\mathrm{T}$ lymphocytes $[32,64,65]$. Given the interest in using $p 16^{I N K 4 a}$ expression as an aging biomarker, a rodent 


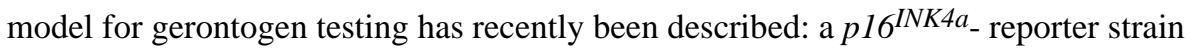
featuring firefly luciferase knocked-in to the endogenous $p 16^{I N K 4 a}$ promoter [29] (Figure 3).

The role of the epigenome in aging is an exciting new area of aging research, and correspondingly, measurements of cell epigenetic state, especially DNA methylation, are being advanced as biomarkers of aging. It has been known for decades that DNA methylation at many loci changes in cells and specific tissues with aging [66-68]. Recently, however, a few groups have employed unbiased, genome-wide approaches to identify DNA methylation signatures of aging reflecting methylation state at many loci throughout the genome. For example, an arraybased methylation score on blood DNA from 656 patients, showed a very strong correlation with chronological age $\left(\mathrm{r}^{2}>0.9\right)$ that persisted in an independent validation cohort [69]. Other groups have similarly noted diverse changes in DNA methylation using other unbiased approaches [70-72]. While this technology is still quite new, these approaches appear to have some advantages including the easy accessibility to DNA from peripheral blood, possible utility in non-hematopoietic tissues and a strong correlation with chronological aging. While an arraybased format might be too expensive for widespread use in large trials, it is likely DNA methylation tests could be adapted to less costly formats (e.g. qPCR) for more generalized use.

The limitations of this approach are still being determined. For example, the effects of intercurrent illness and certain drugs (e.g. DNA damaging agents, DNA methyltransferase inhibitors) on DNA methylation in vivo are largely unknown, and could confound the analysis when used in unselected populations. Perhaps the most significant concern, however, is the link, if any, between DNA methylation and aging physiology. A skeptic might argue, for example, that changes in DNA methylation at random loci may occur sporadically but at a fixed aggregate rate, and therefore 'drift' of the epigenome may indicate little more than the passage of time. Disparate data in fact do suggest that some changes in DNA methylation with aging are random [73-75]. Therefore, while an excellent marker of chronological age, such a test would not provide a good measure of physiological age unless changes in DNA methylation played a causal role in age-related phenotypes. Some promise along these lines comes from the finding that changes in DNA methylation with aging strongly correlate with changes in RNA expression of nearby genes [69], and appear to be associated with specific molecular pathways, for example mitogen activated protein kinase (MAPK) signaling [76]. Of interest with regard to senescence, altered DNA methylation occurs with aging at loci that are regulated by PcG member, enhancer of zeste homolog 2 (EZH2) [76], which is known to play a key role in repression of the CDKN2a locus and maintenance of stem cell self-renewal. Correspondingly, the epigenetic state of hematopoietic stem cells is a major determinant of the physiological age of these cells in vivo [77], further supporting a causal relationship between epigenetic modifications and functional aging. We are unaware of any published efforts to use DNA methylation status to assess a toxicant's potential gerontogenicity, but expect such studies will be soon forthcoming. 


\section{Using Biomarkers to Measure Gerontogenic Effect}

These new biomarkers have permitted early efforts to identify an exposure's gerontogenic effect. Gerontogens can be classified into a few broad subtypes. One class of gerontogens would be environmental agents (such as arsenic, benzenes, etc.) where exposures to humans are typically inadvertent. This class might also include some non-chemical exposures such as ionizing radiation or UV light. A second class contains exposures that occur intentionally, whether it is for enjoyment (e.g. cigarette smoke) or as side-effects of a therapeutic treatment (e.g. cytotoxic chemotherapy and HIV therapy). Some alterations in dietary intake or exercise might overlap with this class. Lastly, a third class of potential gerontogen might be forms of psychological stress. Some evidence suggests that neurochemical changes induced by chronic stress can affect human physiology in diverse ways, and could plausibly be gerontogenic.

\section{Incident Toxicants such as Arsenic, Benzenes}

Arsenic is a common toxicant found in ground water that has been linked to age-related phenotypes including skin and bladder cancer, type II diabetes, neurodegenerative disease and atherosclerosis [78, 79]. In both rodents and humans, arsenic has been reported to decrease aspects of DNA repair [80,81], suggesting a plausible link to senescence and physiologic aging. Recent work using the $p 16^{L U C}$ - reporter allele has shown a modest effect of arsenic exposure on the rate of $p 16^{I N K 4 a}$ accumulation in vivo with aging [34]. This effect might be due to indirect effects on DNA damage repair or direct, as yet poorly understood, pro-aging effects of arsenic that are DNA damage independent. Compared to other more direct DNA damaging exposures, the effects of arsenic on senescence markers at the organismal level are subtle, although more pronounced pro-aging effects in specific tissue compartments (e.g. pancreatic islets) cannot be excluded by this analysis.

Benzene exposure occurs from tobacco smoke, car exhaust and industrial emissions [82] and has been linked to age-related cancers (e.g. non-Hodgkin's lymphoma and leukemia [83]). Benzene exposure may lead to leukocyte telomere shortening [84, 85], suggesting chronic exposure could promote hematopoietic aging through the accumulation of senescent cells in vivo, and therefore benzene may be an environmental gerontogen. Many other incidental exposures (e.g. Polychlorinated Biphenyls (PCBs), lead, nitrosamines, pesticides etc.) have been related to chronic human diseases, and could be considered candidate gerontogens that merit further assessment with regard to effects on aging biomarkers. Similar to arsenic, little is known about the molecular mechanisms leading to the age-related phenotypes.

\section{lonizing Radiation, UV Light}

Ultraviolet light leads to age-related pathologies of the skin. There is strong evidence indicating UV light accelerates photoaging and skin cancer [86, 87], in part through direct DNA damage (e.g. the formation of pyrimidine dimers [88]). Exposure to ionizing radiation (IR) occurs in medical, occupational and industrial settings, and produces single and doublestrand DNA breaks that appear to promote cellular and organismal aging. Excess IR exposure clearly causes a number of cancers, but also is associated with other age-related pathologies as well as a shortened lifespan $[89,90]$. Both types of radiation appear to 
promote molecular aging, causing chronic changes in exposed tissues in the expression of multiple senescence biomarkers including expression of SASP factors [91, 92], LTL shortening [24, 93], and induction of $p 16^{I N K 4 a}$ and other senescence-associated tumor suppressor genes $[34,94]$. We believe these toxicological results add to compelling results from other systems to suggest that chronic DNA damage promotes physiological aging.

\section{Cigarette Smoke}

Cigarette smoke contains over 4,000 potential toxicants and a significant smoking history decreases a human lifespan on average by 7 years [95]. Moreover, exposure to both primary and secondary smoke is associated with human diseases, including atherosclerosis, cancer and emphysema [95, 96]. Smoking has also been shown to decrease capillary blood flow, contributing to the higher rate of facial wrinkling in smokers [97]. Research suggests that mutagens in cigarette smoke, including formaldehyde, carbon monoxide, and nicotine, directly promote DNA damage $[98,99]$ but also have DNA damage-independent toxicities. In humans, chronic cigarette smoke exposure is associated with increased $p 16^{I N K 4 a}$ expression and shorter LTL [32, 58, 64, 100, 101]. Moreover, using the serially imaged p16 ${ }^{L U C}$ animal model [34], there is a pronounced and direct effect of cigarette smoke on in vivo $p 16^{I N K 4 a}$ expression. Of particular interest, the gerontogenic effects of cigarette smoke were most pronounced in tissues that received the greatest exposure. Consistent with the known patterns of exposure using this model [102], mice exposed in smoking chambers do not exhibit a significant induction of senescence markers in the lung, but rather this effect is largely confined to the nasal cavities and upper airways (Figure 3) [34]. These data, as well as extensive human epidemiologic results, suggest that cigarette smoking is a potent gerontogen: likely the most important age-promoting exposure from a public health point of view.

\section{Cytotoxic Chemotherapy}

Since chemotherapy drugs used to treat neoplasms often work through the induction of DNA damage, it is not surprising that such exposures appear to be gerontogenic. For example, serial treatments with chemotherapy promote 'bone marrow exhaustion', which is associated with decreased production of circulating red and white blood cells, an age-associated phenotype of the bone marrow causes lasting non-hematologic toxicities in cancer survivors; some are manifest as an acceleration of an aging phenotype including frailty and cognitive decline [103]. Given the potential for gerontogenic effect of such drugs, combined with the therapeutic need to use such agents in a curative manner in patients with cancer, recently there has been significant interest in the oncologic community in the measurement and quantification of chemotherapy's gerontogenicity. Toward that end, several SA-biomarkers were measured in patients undergoing treatment with cytotoxic agents for breast cancer. In conclusion, adjuvant use of anthracyclines and alkylating agents induced a pronounced acceleration of molecular aging comparable to 10-15 years of chronologic aging as manifested by increased expression of $p 16^{I N K 4 a}$ and SA-cytokines [51]. The ability to measure the age-promoting effects of chemotherapy will be important to routine oncologic care, allowing clinicians to balance the long-term gerontogenic effects with the intended therapeutic effects of such agents. 


\section{Obesity, Diet and Exercise}

As of 2010, 36\% of the U.S adults and 17\% of children were considered obese, which has been suggested to lead to age-related diseases such as cancer, cardiovascular disease, and diabetes [104-106]. Severe obesity is also associated with increased mortality rates compared with normal weight $[107,108]$. In many experimentally housed species, including mammals, caloric restriction has been shown to slow aging and result in a longer lifespan [31, 109]. Therefore, limited caloric intake is generally considered anti-aging, whereas excess calories might be considered pro-aging. Several studies investigated this issue with regard to expression of $p 16^{I N K 4 a}$. There was a slower rate of increase in $p 16^{I N K 4 a}$ expression in most tissues of calorically restricted rodents [31], but found no acceleration in the rate of $p 16^{I N K 4 a}$ expression in mice on a high fat diet, which induced obesity [34]. While the finding in calorically restricted animals fits the accepted paradigm, it is unclear why high-fat diet and diet-induced obesity did not lead to increased $p 16^{I N K 4 a}$ expression, as expected. It is possible measurement with whole-body luciferase imaging is too insensitive to see altered expression in specific cellular compartments of physiological importance (e.g. pancreatic islets or tissue stem cells); or alternatively, perhaps high-fat diet is not as gerontogenic as might have been expected. Accordingly, no correlation was found between body-mass index (BMI), a crude measure of obesity, and p16 $6^{I N K 4 a}$ expression in humans [32], and a mildly increased BMI is not associated with excess mortality in humans $[107,110]$. Some work using telomere length as a biomarker for aging has given different results. For example, a few human studies have suggested a modest, inverse correlation between a diet high in fat and processed meats with telomere length $[108,111]$. Moreover, telomere length has been inversely correlated with BMI and hip circumference [108, 111]. It is unclear why different senescence biomarkers appear to yield different results with regard to the effect of high-fat diet and obesity on physiological age.

Studying the effect of exercise on aging in humans is also complex. Advanced physiologic age is clinically manifest as the syndrome of frailty; frailty is in turn characterized by decreased lean body mass, strength, endurance, balance, walking performance, and low activity [112]. Given that an end result of aging is a loss of the ability to exercise, determining any causal relationship between exercise and the pace of aging is difficult. Using biomarkers of physiologic age prior to the onset of advanced physiologic age allows an opportunity to evaluate the effect of exercise of aging. That exercise results in a younger physiologic age as measured by aging biomarkers has been suggested through a variety of approaches including reduced $p 16^{I N K 4 a}$ expression [32, 113], longer telomere length [113$116]$, and reduced senescence associated cytokines $[115,117]$ among exercisers.

\section{Psychological Stress}

Extensive research has suggested that chronic psychological stress may lead to age-related pathologies such as cardiovascular disease, decreased immunity, and neural degeneration $[118,119]$. For example, children that are raised in stressful environments such as poverty or abuse exhibit modestly increased rates of vascular and autoimmune disease [120]. Perceived psychological stress (e.g. from caring for a chronically ill child) has been suggested to lead to decreased telomerase activity and lower telomere length [121]. While the notion that the gerontogenic effects of psychological stress can be quantified using aging biomarkers is 
highly exciting, this line of research, however, is still in its infancy and a skeptic would concede that a gerontogenic activity of psychological stress in humans has not been established.

\section{Concluding Remarks}

In summary, while human aging is complex, we believe the field has made important recent strides toward a molecular understanding of aging physiology. In particular, recent observations suggest that chronic cellular stress/damage leads to a loss of tissue replicative capacity and the promotion of cellular senescence in vivo, thereby causing several ageinduced phenotypes. This senescence model of aging makes several important predictions, one of which is that the measurement of SA markers (e.g. LTL, $p 16^{I N K 4 a}$ ) with aging can provide a manner to quantify molecular aging. If correct, this understanding suggests that these biomarkers could be used to explicitly measure the age-promoting effect of complex gerontogens such as environmental exposures, altered diet and psychological trauma. It is possible that others measurements of molecular age such as determinations of DNA methylation may also provide useful biomarkers for this purpose. Just as the concept of a carcinogen has provided a foundation for cancer biology, the concept of a gerontogen, and its measurement using appropriate animal models and human biomarkers, will be critical to a modern understanding of human aging.

\section{GLOSSARY}

Ames
mutagenesis
test

Biomarker

\section{Cellular} senescence
A biological assay used to test the mutagenic potential of a specific toxicant using bacteria deficient in histidine synthesis. Toxicant-treated bacteria are plated on low histidine plates, with colony formation evidence of mutation allowing for histidine synthesis. The number of bacterial colonies is related to the toxicant's mutagenicity.

A biological indicator (e.g. expression of a protein or transcript) of a physiologic process of interest. Generally, optimal biomarkers are causally associated with the biological process they are intended to monitor. For example, LDL cholesterol levels are a good biomarker of atherosclerosis since they play a direct role in its pathogenesis. Fever, on the other hand, is a poor biomarker of infection, since it plays no causal role in infection. Measures that reduce LDL cholesterol will reduce atherosclerosis, whereas anti-pyretics will not treat an infection.

A phenomenon where replication-competent cells permanently stop dividing in response to a variety of cellular stresses. Several markers of senescence are known including expression of the $p 16^{I N K 4 a}$ tumor suppressor gene and senescence-associated cytokines (see "SASP"). Generally, senescence is considered distinct from terminal differentiation in that the former is stochastic and the latter is a programmed cellular event. 
Frailty In geriatric care, it is the state of having low physiological reserve in the absence of overt disease. Frailty is characterized by poor wound healing and tissue repair; sarcopenia and decreased exercise tolerance; and increased susceptibility to age-associated diseases.

\section{Gerontogen}

Healthspan

Progeria

Quiescence

Sarcopenia

Senescenceassociated secretory phenotype (SASP)
An environmental stimulus, exposure or toxicant that accelerates the rate of molecular aging.

The period of the organismal lifespan spent in good health. Therapeutic measures to extend the healthspan are generally considered more desirable than those that extend lifespan only.

Any of several genetic disorders associated with premature physiological aging. Examples include disorders of DNA metabolism (e.g. Ataxia-Telangectasia, Werner syndrome) and laminopathies (Hutchison-Guilford syndrome).

The state where replication-competent cells temporarily exit the cell cycle, generally resting in the G0 or G1 state. As opposed to senescent cells, quiescent cells are capable of cell cycle re-entry when stimulated with mitogens.

The age-associated loss of skeletal muscle mass.

A large suite of cytokines, growth factors, and inflammation-associated proteins that are secreted from a senescent cell.

\section{REFERENCES}

1. Dillin A, Crawford DK, Kenyon C. Timing requirements for insulin/IGF-1 signaling in C. elegans. Science. 2002; 298(5594):830-4. [PubMed: 12399591]

2. Tatar M, et al. A mutant Drosophila insulin receptor homolog that extends life-span and impairs neuroendocrine function. Science. 2001; 292(5514):107-10. [PubMed: 11292875]

3. Vevea JD, et al. Inheritance of the fittest mitochondria in yeast. Trends Cell Biol. 24(1):53-60. [PubMed: 23932848]

4. Jin C, et al. Histone demethylase UTX-1 regulates C. elegans life span by targeting the insulin/ IGF-1 signaling pathway. Cell Metab. 14(2):161-72. [PubMed: 21803287]

5. Longo VD, et al. Replicative and chronological aging in Saccharomyces cerevisiae. Cell Metab. 16(1):18-31. [PubMed: 22768836]

6. Liang H, et al. Genetic mouse models of extended lifespan. Exp Gerontol. 2003; 38(11-12):135364. [PubMed: 14698816]

7. Jeck WR, Siebold AP, Sharpless NE. Review: a meta-analysis of GWAS and age-associated diseases. Aging Cell. 2012; 11(5):727-31. [PubMed: 22888763]

8. Lunetta KL, et al. Genetic correlates of longevity and selected age-related phenotypes: a genomewide association study in the Framingham Study. BMC Med Genet. 2007; 8(Suppl 1):S13. [PubMed: 17903295]

9. Anisimov VN, et al. Gender differences in metformin effect on aging, life span and spontaneous tumorigenesis in 129/Sv mice. Aging (Albany NY). 2010; 2(12):945-58. [PubMed: 21164223] 
10. Harrison DE, et al. Rapamycin fed late in life extends lifespan in genetically heterogeneous mice. Nature. 2009; 460(7253):392-5. [PubMed: 19587680]

11. Butlin HT. Three Lectures on Cancer of the Scrotum in Chimney-Sweeps and Others: Delivered at the Royal College of Surgeons of England. Br Med J. 1892; 2(1645):66-71.

12. Doll R, Hill AB. Lung cancer and other causes of death in relation to smoking; a second report on the mortality of British doctors. Br Med J. 1956; 2(5001):1071-81. [PubMed: 13364389]

13. Perls T, Puca A. The genetics of aging-- implications for pharmacogenomics. Pharmacogenomics. 2002; 3(4):469-84. [PubMed: 12164771]

14. Martin GM. Interactions of aging and environmental agents: the gerontological perspective. Prog Clin Biol Res. 1987; 228:25-80. [PubMed: 3554264]

15. Kirkwood TB. Understanding the odd science of aging. Cell. 2005; 120(4):437-47. [PubMed: 15734677]

16. Hoeijmakers JH. DNA damage, aging, and cancer. N Engl J Med. 2009; 361(15):1475-85. [PubMed: 19812404]

17. Long GG, et al. Alternative mouse models for carcinogenicity assessment: industry use and issues with pathology interpretation. Toxicol Pathol. 2010; 38(1):43-50. [PubMed: 19915137]

18. Campisi J. Senescent cells, tumor suppression, and organismal aging: good citizens, bad neighbors. Cell. 2005; 120(4):513-22. [PubMed: 15734683]

19. Herbig U, et al. Telomere shortening triggers senescence of human cells through a pathway involving ATM, p53, and p21(CIP1), but not p16(INK4a). Mol Cell. 2004; 14(4):501-13. [PubMed: 15149599]

20. Allsopp RC, et al. Telomere length predicts replicative capacity of human fibroblasts. Proc Natl Acad Sci U S A. 1992; 89(21):10114-8. [PubMed: 1438199]

21. Serrano M, et al. Oncogenic ras provokes premature cell senescence associated with accumulation of p53 and p16INK4a. Cell. 1997; 88(5):593-602. [PubMed: 9054499]

22. Zhu J, et al. Senescence of human fibroblasts induced by oncogenic Raf. Genes Dev. 1998; 12(19): 2997-3007. [PubMed: 9765202]

23. Meng A, et al. Ionizing radiation and busulfan induce premature senescence in murine bone marrow hematopoietic cells. Cancer Res. 2003; 63(17):5414-9. [PubMed: 14500376]

24. Bartkova J, et al. Oncogene-induced senescence is part of the tumorigenesis barrier imposed by DNA damage checkpoints. Nature. 2006; 444(7119):633-7. [PubMed: 17136093]

25. Chen $\mathrm{H}$, et al. Polycomb protein Ezh2 regulates pancreatic beta-cell Ink4a/Arf expression and regeneration in diabetes mellitus. Genes Dev. 2009; 23(8):975-85. [PubMed: 19390090]

26. Kim WY, Sharpless NE. The regulation of INK4/ARF in cancer and aging. Cell. 2006; 127(2): 265-75. [PubMed: 17055429]

27. Bracken AP, et al. The Polycomb group proteins bind throughout the INK4A-ARF locus and are disassociated in senescent cells. Genes Dev. 2007; 21(5):525-30. [PubMed: 17344414]

28. Dai CY, Enders GH. p16 INK4a can initiate an autonomous senescence program. Oncogene. 2000; 19(13):1613-22. [PubMed: 10763818]

29. Burd CE, et al. Monitoring Tumorigenesis and Senescence In Vivo with a p16(INK4a)-Luciferase Model. Cell. 2013; 152(1-2):340-51. [PubMed: 23332765]

30. Wei W, et al. Loss of retinoblastoma but not p16 function allows bypass of replicative senescence in human fibroblasts. EMBO Rep. 2003; 4(11):1061-6. [PubMed: 14566323]

31. Krishnamurthy J, et al. Ink4a/Arf expression is a biomarker of aging. J Clin Invest. 2004; 114(9): 1299-307. [PubMed: 15520862]

32. Liu Y, et al. Expression of p16(INK4a) in peripheral blood T-cells is a biomarker of human aging. Aging Cell. 2009; 8(4):439-48. [PubMed: 19485966]

33. Zindy F, et al. Expression of the p16INK4a tumor suppressor versus other INK4 family members during mouse development and aging. Oncogene. 1997; 15(2):203-11. [PubMed: 9244355]

34. Sorrentino JA, et al. p16INK4a reporter mice reveal age-promoting effects of environmental toxicants. J Clin Invest. 2014; 124(1):169-73. [PubMed: 24334456]

35. Molofsky AV, et al. Increasing p16INK4a expression decreases forebrain progenitors and neurogenesis during ageing. Nature. 2006; 443(7110):448-52. [PubMed: 16957738] 
36. Janzen V, et al. Stem-cell ageing modified by the cyclin-dependent kinase inhibitor p16INK4a. Nature. 2006; 443(7110):421-6. [PubMed: 16957735]

37. Signer RA, et al. Aging and cancer resistance in lymphoid progenitors are linked processes conferred by p16Ink4a and Arf. Genes Dev. 2008; 22(22):3115-20. [PubMed: 19056891]

38. Sousa-Victor P, et al. Geriatric muscle stem cells switch reversible quiescence into senescence. Nature. 506(7488):316-21. [PubMed: 24522534]

39. Krishnamurthy J, et al. p16INK4a induces an age-dependent decline in islet regenerative potential. Nature. 2006; 443(7110):453-7. [PubMed: 16957737]

40. Berent-Maoz B, et al. Fibroblast growth factor-7 partially reverses murine thymocyte progenitor aging by repression of Ink4a. Blood. 2012; 119(24):5715-21. [PubMed: 22555975]

41. Chen $\mathrm{H}$, et al. PDGF signalling controls age-dependent proliferation in pancreatic beta-cells. Nature. 2011; 478(7369):349-55. [PubMed: 21993628]

42. Baker DJ, et al. Clearance of p16Ink4a-positive senescent cells delays ageing-associated disorders. Nature. 2011; 479(7372):232-6. [PubMed: 22048312]

43. Sharpless NE, DePinho RA. How stem cells age and why this makes us grow old. Nat Rev Mol Cell Biol. 2007; 8(9):703-13. [PubMed: 17717515]

44. Davalos AR, et al. Senescent cells as a source of inflammatory factors for tumor progression. Cancer and Metastasis Reviews. 2010; 29(2):273-283. [PubMed: 20390322]

45. Lesne $S$, et al. A specific amyloid-beta protein assembly in the brain impairs memory. Nature. 2006; 440(7082):352-7. [PubMed: 16541076]

46. Kawarabayashi T, et al. Age-dependent changes in brain, CSF, and plasma amyloid (beta) protein in the Tg2576 transgenic mouse model of Alzheimer's disease. J Neurosci. 2001; 21(2):372-81. [PubMed: 11160418]

47. Carroll KK, Guthrie N, Ravi K. Dolichol: function, metabolism, and accumulation in human tissues. Biochem Cell Biol. 1992; 70(6):382-4. [PubMed: 1449704]

48. Marino M, et al. Accumulation of dolichol and impaired signal transduction in aging. Aging (Milano). 1997; 9(6):433-4. [PubMed: 9553626]

49. Dimri GP, et al. A biomarker that identifies senescent human cells in culture and in aging skin in vivo. Proc Natl Acad Sci U S A. 1995; 92(20):9363-7. [PubMed: 7568133]

50. Tchkonia $\mathrm{T}$, et al. Cellular senescence and the senescent secretory phenotype: therapeutic opportunities. J Clin Invest. 2013; 123(3):966-72. [PubMed: 23454759]

51. Sanoff H, et al. Effect of Cytotoxic Chemotherapy on Markers of Molecular Age in Patients with Breast Cancer. J Natl Cancer Inst. 2014

52. Herbig U, et al. Cellular senescence in aging primates. Science. 2006; 311(5765):1257. [PubMed: 16456035]

53. Chen W, et al. Longitudinal versus cross-sectional evaluations of leukocyte telomere length dynamics: age-dependent telomere shortening is the rule. J Gerontol A Biol Sci Med Sci. 2011; 66(3):312-9. [PubMed: 21310811]

54. Lin J, et al. Analyses and comparisons of telomerase activity and telomere length in human T and B cells: insights for epidemiology of telomere maintenance. J Immunol Methods. 2010; 352(1-2): 71-80. [PubMed: 19837074]

55. Longo DL. Telomere dynamics in aging: much ado about nothing? J Gerontol A Biol Sci Med Sci. 2009; 64(9):963-4. [PubMed: 19505961]

56. Van Ziffle JA, Baerlocher GM, Lansdorp PM. Telomere length in subpopulations of human hematopoietic cells. Stem Cells. 2003; 21(6):654-60. [PubMed: 14595125]

57. Allsopp RC, et al. Effect of TERT over-expression on the long-term transplantation capacity of hematopoietic stem cells. Nat Med. 2003; 9(4):369-71. [PubMed: 12669037]

58. Valdes AM, et al. Obesity, cigarette smoking, and telomere length in women. Lancet. 2005; 366(9486):662-4. [PubMed: 16112303]

59. Muezzinler A, Zaineddin AK, Brenner H. A systematic review of leukocyte telomere length and age in adults. Ageing Res Rev. 2013; 12(2):509-19. [PubMed: 23333817]

60. Melk A, et al. Cell senescence in rat kidneys in vivo increases with growth and age despite lack of telomere shortening. Kidney Int. 2003; 63(6):2134-43. [PubMed: 12753300] 
61. Melk A, et al. Expression of p16INK4a and other cell cycle regulator and senescence associated genes in aging human kidney. Kidney Int. 2004; 65(2):510-20. [PubMed: 14717921]

62. Ressler S, et al. p16INK4A is a robust in vivo biomarker of cellular aging in human skin. Aging Cell. 2006; 5(5):379-89. [PubMed: 16911562]

63. Waaijer ME, et al. The number of p16INK4a positive cells in human skin reflects biological age. Aging Cell. 2012; 11(4):722-5. [PubMed: 22612594]

64. Nelson JA, et al. Expression of p16(INK4a) as a biomarker of T-cell aging in HIV-infected patients prior to and during antiretroviral therapy. Aging Cell. 2012; 11(5):916-8. [PubMed: 22738669]

65. Liu Y, et al. INK4/ARF transcript expression is associated with chromosome 9p21 variants linked to atherosclerosis. PLoS One. 2009; 4(4):e5027. [PubMed: 19343170]

66. Wilson VL, Jones PA. DNA methylation decreases in aging but not in immortal cells. Science. 1983; 220(4601):1055-7. [PubMed: 6844925]

67. Maegawa S, et al. Widespread and tissue specific age-related DNA methylation changes in mice. Genome Res. 2010; 20(3):332-40. [PubMed: 20107151]

68. Romanov GA, Vanyushin BF. Methylation of reiterated sequences in mammalian DNAs. Effects of the tissue type, age, malignancy and hormonal induction. Biochim Biophys Acta. 1981; 653(2): 204-18. [PubMed: 7225396]

69. Hannum G, et al. Genome-wide methylation profiles reveal quantitative views of human aging rates. Mol Cell. 2013; 49(2):359-67. [PubMed: 23177740]

70. Bell JT, et al. Epigenome-wide scans identify differentially methylated regions for age and agerelated phenotypes in a healthy ageing population. PLoS Genet. 2012; 8(4):e1002629. [PubMed: 22532803]

71. Koch CM, Wagner W. Epigenetic-aging-signature to determine age in different tissues. Aging (Albany NY). 2011; 3(10):1018-27. [PubMed: 22067257]

72. Garagnani P, et al. Methylation of ELOVL2 gene as a new epigenetic marker of age. Aging Cell. 2012; 11(6):1132-4. [PubMed: 23061750]

73. Thompson RF, et al. Tissue-specific dysregulation of DNA methylation in aging. Aging Cell. 2010; 9(4):506-18. [PubMed: 20497131]

74. Fraga MF, et al. Epigenetic differences arise during the lifetime of monozygotic twins. Proc Natl Acad Sci U S A. 2005; 102(30):10604-9. [PubMed: 16009939]

75. West J, Widschwendter M, Teschendorff AE. Distinctive topology of age-associated epigenetic drift in the human interactome. Proc Natl Acad Sci U S A. 2013; 110(35):14138-43. [PubMed: 23940324]

76. McClay JL, et al. A methylome-wide study of aging using massively parallel sequencing of the methyl-CpG-enriched genomic fraction from blood in over 700 subjects. Hum Mol Genet. 2013

77. Wahlestedt M, et al. An epigenetic component of hematopoietic stem cell aging amenable to reprogramming into a young state. Blood. 2013; 121(21):4257-64. [PubMed: 23476050]

78. Kapaj S, et al. Human health effects from chronic arsenic poisoning--a review. J Environ Sci Health A Tox Hazard Subst Environ Eng. 2006; 41(10):2399-428. [PubMed: 17018421]

79. Migliore L, Coppede F. Environmental-induced oxidative stress in neurodegenerative disorders and aging. Mutat Res. 2009; 674(1-2):73-84. [PubMed: 18952194]

80. Banerjee M, et al. DNA repair deficiency leads to susceptibility to develop arsenic-induced premalignant skin lesions. Int J Cancer. 2008; 123(2):283-7. [PubMed: 18386817]

81. Andrew AS, et al. Arsenic exposure is associated with decreased DNA repair in vitro and in individuals exposed to drinking water arsenic. Environ Health Perspect. 2006; 114(8):1193-8. [PubMed: 16882524]

82. Wallace LA. Major sources of benzene exposure. Environ Health Perspect. 1989; 82:165-9. [PubMed: 2477239]

83. Smith MT, Jones RM, Smith AH. Benzene exposure and risk of non-Hodgkin lymphoma. Cancer Epidemiol Biomarkers Prev. 2007; 16(3):385-91. [PubMed: 17337645] 
84. Hoxha M, et al. Association between leukocyte telomere shortening and exposure to traffic pollution: a cross-sectional study on traffic officers and indoor office workers. Environ Health. 2009; 8:41. [PubMed: 19772576]

85. Zhang X, et al. Environmental and occupational exposure to chemicals and telomere length in human studies. Occup Environ Med. 2013; 70(10):743-9. [PubMed: 23775864]

86. Kligman LH. Photoaging. Manifestations, prevention, and treatment. Clin Geriatr Med. 1989; 5(1): 235-51. [PubMed: 2646001]

87. Scharffetter-Kochanek K, et al. Photoaging of the skin from phenotype to mechanisms. Exp Gerontol. 2000; 35(3):307-16. [PubMed: 10832052]

88. Setlow RB, Carrier WL. Pyrimidine dimers in ultraviolet-irradiated DNA's. J Mol Biol. 1966; 17(1):237-54. [PubMed: 4289765]

89. Cole LJ, Nowell PC, Arnold JS. Late effects of x-radiation. The influence of dose fractionation on life span, leukemia, and nephrosclerosis incidence in mice. Radiat Res. 1960; 12:173-85. [PubMed: 13811124]

90. Upton AC. Ionizing radiation and the aging process; a review. J Gerontol. 1957; 12(3):306-13. [PubMed: 13463302]

91. Rodier F, et al. Persistent DNA damage signalling triggers senescence-associated inflammatory cytokine secretion. Nat Cell Biol. 2009; 11(8):973-9. [PubMed: 19597488]

92. Freund A, Patil CK, Campisi J. p38MAPK is a novel DNA damage response-independent regulator of the senescence-associated secretory phenotype. EMBO J. 2011; 30(8):1536-48. [PubMed: 21399611]

93. Lakin ND, Jackson SP. Regulation of p53 in response to DNA damage. Oncogene. 1999; 18(53): 7644-55. [PubMed: 10618704]

94. Marcoux S, et al. Expression of the senescence marker p16INK4a in skin biopsies of acute lymphoblastic leukemia survivors: a pilot study. Radiat Oncol. 2013; 8(1):252. [PubMed: 24171943]

95. Bernhard D, et al. Cigarette smoke--an aging accelerator? Exp Gerontol. 2007; 42(3):160-5. [PubMed: 17084574]

96. Ito K, Barnes PJ. COPD as a disease of accelerated lung aging. Chest. 2009; 135(1):173-80. [PubMed: 19136405]

97. Grady D, Ernster V. Does cigarette smoking make you ugly and old? Am J Epidemiol. 1992; 135(8):839-42. [PubMed: 1585896]

98. DeMarini DM. Genotoxicity of tobacco smoke and tobacco smoke condensate: a review. Mutat Res. 2004; 567(2-3):447-74. [PubMed: 15572290]

99. Pfeifer GP, et al. Tobacco smoke carcinogens, DNA damage and p53 mutations in smokingassociated cancers. Oncogene. 2002; 21(48):7435-51. [PubMed: 12379884]

100. Mirabello L, et al. The association between leukocyte telomere length and cigarette smoking, dietary and physical variables, and risk of prostate cancer. Aging Cell. 2009; 8(4):405-13. [PubMed: 19493248]

101. Song Z, et al. Lifestyle impacts on the aging-associated expression of biomarkers of DNA damage and telomere dysfunction in human blood. Aging Cell. 2010; 9(4):607-15. [PubMed: 20560902]

102. Huvenne W, et al. Different regulation of cigarette smoke induced inflammation in upper versus lower airways. Respir Res. 2010; 11:100. [PubMed: 20650015]

103. Ness KK, et al. Physiologic frailty as a sign of accelerated aging among adult survivors of childhood cancer: a report from the st jude lifetime cohort study. J Clin Oncol. 2013; 31(36): 4496-503. [PubMed: 24248696]

104. Flegal KM, et al. Cause-specific excess deaths associated with underweight, overweight, and obesity. JAMA. 2007; 298(17):2028-37. [PubMed: 17986696]

105. Ogden CL, et al. Prevalence of obesity among adults: United States, 2011-2012. NCHS Data Brief. 2013; (131):1-8.

106. Calle EE, et al. Overweight, obesity, and mortality from cancer in a prospectively studied cohort of U.S. adults. N Engl J Med. 2003; 348(17):1625-38. [PubMed: 12711737] 
107. Flegal KM, et al. Association of all-cause mortality with overweight and obesity using standard body mass index categories: a systematic review and meta-analysis. JAMA. 2013; 309(1):71-82. [PubMed: 23280227]

108. Nettleton JA, et al. Dietary patterns, food groups, and telomere length in the Multi-Ethnic Study of Atherosclerosis (MESA). Am J Clin Nutr. 2008; 88(5):1405-12. [PubMed: 18996878]

109. Masoro EJ. Overview of caloric restriction and ageing. Mech Ageing Dev. 2005; 126(9):913-922. [PubMed: 15885745]

110. Flegal KM, et al. Excess deaths associated with underweight, overweight, and obesity. JAMA. 2005; 293(15):1861-7. [PubMed: 15840860]

111. Cassidy A, et al. Associations between diet, lifestyle factors, and telomere length in women. Am J Clin Nutr. 2010; 91(5):1273-80. [PubMed: 20219960]

112. Fried LP, et al. Frailty in older adults: evidence for a phenotype. J Gerontol A Biol Sci Med Sci. 2001; 56(3):M146-56. [PubMed: 11253156]

113. Werner C, et al. Physical exercise prevents cellular senescence in circulating leukocytes and in the vessel wall. Circulation. 2009; 120(24):2438-47. [PubMed: 19948976]

114. LaRocca TJ, Seals DR, Pierce GL. Leukocyte telomere length is preserved with aging in endurance exercise-trained adults and related to maximal aerobic capacity. Mech Ageing Dev. 2010; 131(2):165-7. [PubMed: 20064545]

115. Simpson RJ, et al. Senescent phenotypes and telomere lengths of peripheral blood T-cells mobilized by acute exercise in humans. Exerc Immunol Rev. 2010; 16:40-55. [PubMed: 20839490]

116. Ludlow AT, et al. Relationship between physical activity level, telomere length, and telomerase activity. Med Sci Sports Exerc. 2008; 40(10):1764-71. [PubMed: 18799986]

117. Drela N, Kozdron E, Szczypiorski P. Moderate exercise may attenuate some aspects of immunosenescence. BMC Geriatr. 2004; 4:8. [PubMed: 15456521]

118. McEwen BS. Protective and damaging effects of stress mediators. N Engl J Med. 1998; 338(3): 171-9. [PubMed: 9428819]

119. Liu J, Mori A. Stress, aging, and brain oxidative damage. Neurochem Res. 1999; 24(11):1479-97. [PubMed: 10555789]

120. Miller GE, Chen E, Parker KJ. Psychological Stress in Childhood and Susceptibility to the Chronic Diseases of Aging: Moving Toward a Model of Behavioral and Biological Mechanisms. Psychological Bulletin. 2011; 137(6):959-997. [PubMed: 21787044]

121. Epel ES, et al. Accelerated telomere shortening in response to life stress. Proc Natl Acad Sci U S A. 2004; 101(49):17312-17315. [PubMed: 15574496] 


\section{Highlights}

- Exposures to certain toxicants ('gerontogens') can accelerate physiological aging

- Unequal exposures to gerontogens may cause people to age at different rates

- Markers of senescence show promise as biomarkers to quantify gerontogenic exposures 


\section{Box 1. Outstanding Questions}

- Are there good senescence-independent biomarkers for aging?

- Are there common environmental agents (other than cigarette smoke) that accelerate aging on a population basis?

- Are there common environmental agents that decelerate aging on a population basis?

- Are the pro-aging effects of senescence-promoting gerontogens reversible? Can these affects be therapeutically targeted?

- What human age-associated phenotypes specifically correlate with expression of senescence-associated biomarkers? 


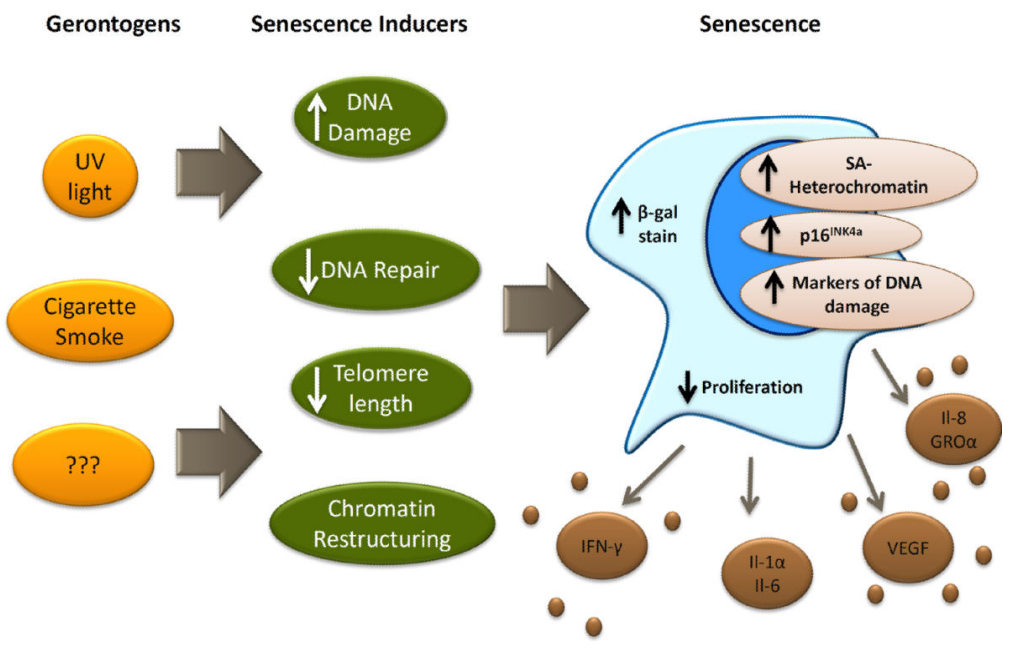

Figure 1. Some gerontogens may promote cellular senescence

Varied external exposures and noxious stimuli (i.e. gerontogens, yellow/orange) may promote aging via the induction of cellular stresses (dark green) that in turn activate the senescence machinery (i.e. $\mathrm{p} 53, \mathrm{p} 16^{\mathrm{INK} 4 \mathrm{a}}$ and other anti-proliferative checkpoints). Senescent cells may express some a combination of the indicated biomarkers (e.g. senescence-associated cytokines, short telomeres, $p 16^{I N K 4 a}$ expression) allowing for their in vivo detection and quantification. Importantly, it is also likely that some gerontogens promote aging in a senescence-independent manner. Abbreviations: UV, ultraviolet light; $\beta$ gal stain, $\beta$-galactosidase stain; SA, senescence associated; IFN- $\gamma$, interferon $\gamma ;$ IL-1a, interleukin 1a; IL-6, interleukin 6; VEGF, Vascular endothelial growth factor; IL-8, interleukin 8; GROa, growth-related oncogene a 


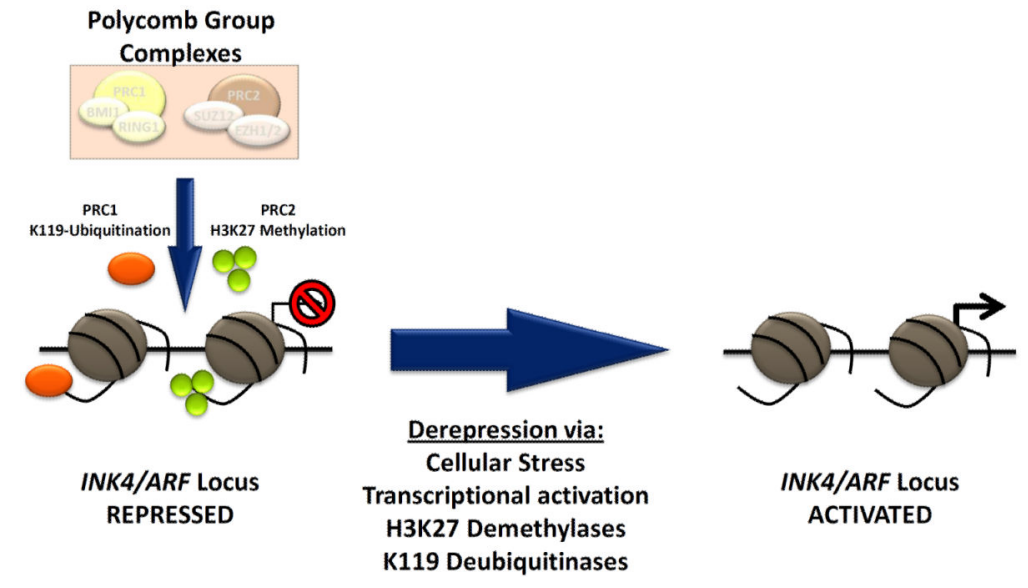

Figure 2. Schematic showing regulation of the INK4a/ARF (CDKN2a) locus

Repression of the locus in healthy, self-renewing cells is mediated by the histone-modifying activities of the PRC1 (protein regulator of cytokinesis 1, orange) and PRC2 (protein regulator of cytokinesis 1, green) Polycomb Group complexes. The PRC1 complex contains BMI1 (B Lymphoma Mo-MLV Insertion Region 1) and ubiquitinates lysine 119 of histone 3 (H3K119), whereas the PRC2 complex, containing EZH2 (enhancer of zeste homolog 2), catalyzes tri-methylation of lysine 27 of histone 3 (H3K27). Both activities promote durable and heritable locus silencing. Activation in response to certain cellular stresses is thought to promote senescence lead to locus de-repression, likely in part through inhibition of PRC1/2 as well as activation of $\mathrm{H} 3$ lysine demethylases and deubiquitinases. Abbreviations: PRC1, protein regulator of cytokinesis 1; PCR2, protein regulator of cytokinesis 1; INK4, inhibitor of cyclin-dependent kinase 4; ARF, alternate reading frame. 
A

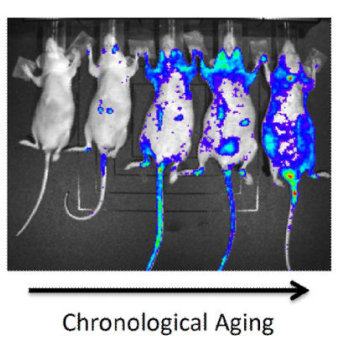

B

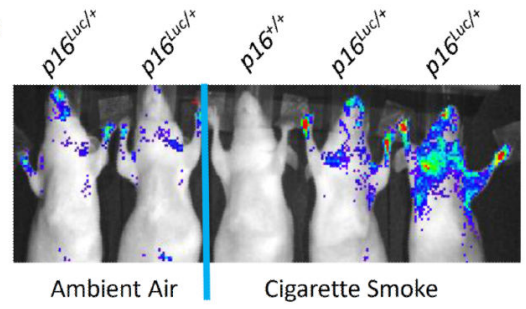

Figure 3. A murine senescence reporter strain for gerontogenicity

The recently published $p 16^{L U C}$ allele featuring firefly luciferase 'knocked in' to the $p 16^{I N K 4 a}$ promoter [29] was used to serially measure $p 16^{I N K 4 a}$ expression in vivo with normal chronological aging (A) or after chronic exposure to cigarette smoke (B). In A, mouse age increases from left to right at $\sim 15$ week intervals from 18 to 96 weeks of age. In $\mathbf{B}$, mice of the indicated genotypes are all of the same age with or without chronic ( 8 months) tobacco exposure [34]. Consistent with the fact the pulmonary exposure to tobacco smoke is poor using chamber inhalation models; note that the gerontogenic effects of cigarette smoking are anatomically localized to the nasal cavities and upper airways. 


\section{Table 1}

Measurable aging biomarkers for mice and humans ${ }^{1}$

\begin{tabular}{|c|c|c|}
\hline Biomarker & Strengths & Weaknesses \\
\hline $\begin{array}{l}\text { Senescence Associated } \beta \text { - } \\
\text { galactosidase stain }\end{array}$ & - Highly validated in vitro & $\begin{array}{l}\text { - Non-quantitative } \\
\text { - Correlation with chronologic aging is undefined } \\
\text { - High background in certain tissues in vivo } \\
\text { - No causal role in aging }\end{array}$ \\
\hline Leukocyte Telomere Length & $\begin{array}{l}\text { - Can be assessed on peripheral blood } \\
\text { - Supported by GWAS, murine studies as } \\
\text { having causal role in some aspects of aging } \\
\text { biology }\end{array}$ & $\begin{array}{l}\text { - Inter-individual heterogeneity is high } \\
\text { - Correlation with chronologic aging is low }\left(\mathrm{R}^{2}<0.2\right) \\
\text { - High quality assays are complex and costly } \\
\text { - Small dynamic range }(\sim 30 \% \text { change })\end{array}$ \\
\hline Il-6, other SA-cytokines & $\begin{array}{l}\text { - Easy to measure in serum from peripheral } \\
\text { blood }\end{array}$ & $\begin{array}{l}\text { - Inter-individual heterogeneity is high } \\
\text { - Correlation with chronologic aging is low }\left(\mathrm{R}^{2}<0.1\right) \\
\text { - Affected by minor inter-current illness } \\
\text { - Causal role in aging unclear }\end{array}$ \\
\hline $\begin{array}{l}\text { p16 }{ }_{\text {iNK4a }} \text { mRNA in T- } \\
\text { lymphocytes }\end{array}$ & $\begin{array}{l}\text { - Validated in vitro and in murine models } \\
\text { - Highly dynamic }(>10 \text {-fold change) } \\
\text { - Chronologic aging } \mathrm{R}^{2} \text { is high }(>0.5) \\
\text { - Supported by GWAS, murine studies as } \\
\text { having causal role in some aspects of aging } \\
\text { biology }\end{array}$ & $\begin{array}{l}\text { - Requires sorted T cells } \\
\text { - RNA marker }\end{array}$ \\
\hline DNA Methylation & $\begin{array}{l}\text { - Easy to quantitate } \\
\text { - Can be assessed on DNA from peripheral } \\
\text { blood } \\
\text { - Chronologic aging } \mathrm{R}^{2} \text { is very high }(0.5 \text { to } 0.9)\end{array}$ & $\begin{array}{l}\text { - Role in aging is unclear } \\
\text { - Array cost is expensive, but may be possible to do } \\
\text { in cheaper PCR format }\end{array}$ \\
\hline
\end{tabular}

${ }^{1}$ Abbreviations: GWAS, Genome wide association study; Il-6, Interleukin-6; SA, senescence associated. 